\title{
Role of Inventory Management on Competitive Advantage of Small and Medium Companies in Thailand
}

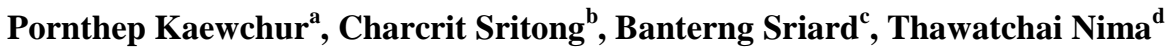 \\ ${ }^{\text {a }}$ Rajamangala University of Technology Suvarnabhumi, Thailand \\ ${ }^{\mathrm{b}}$ Valaya Alongkorn Rajabhat under the Royal Patronage University, Thailand \\ ${ }^{\mathrm{c}, \mathrm{d}}$ Independent Researcher, Thailand

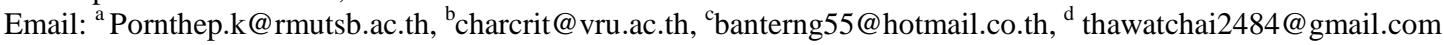

Article History: Received: 10 January2021; Revised: 12 February 2021; Accepted: 27 March 2021; Published online: 20 April 2021

\begin{abstract}
The purposes of this research were to study the inventory management factors affecting the competitive advantage and confirm the inventory management factors affecting the competitive advantage. This research was a mixed methods research. First, the quantitative data was collected from the sample of 280 small and medium companies in Thailand. This research focused on 14 observable variables. Then, the qualitative data was collected from nine key informants who were the experts in the inventory management field. The results indicated that the structural equation model was consistent and harmonious with the empirical data with the model consistency indices as follows: $\chi 2=106.32, \mathrm{df}=69, \chi 2 / \mathrm{df}=1.54, \mathrm{CFI}=$ 0.99 , GFI $=0.95$, SRMR $=0.042$, RMSEA $=0.044$. Furthermore, the inventory control systems had the greatest influence on the competitive advantage, followed by inventory control practices, and information technology, respectively.
\end{abstract}

Index Terms: Inventory Management, Competitive Advantage, Inventory Control Practices

\section{Introduction}

At present, Small and Medium Enterprises (SMEs) are start-ups in expanding into larger businesses. Therefore, to run a successful SMEs business, you must have the ability to do business or have to have experience with expertise in various businesses that will result in business growth. At present, the government sector supports new businesses as a solid foundation for further development into a profitable and competitive business on the global stage. In 2020, Thailand has divided the size of SMEs down to the next level, that is, small enterprises. In the manufacturing sector, the workforce must not exceed 5 people and the annual income is not more than 1.8 million baht, thus promoting many businesses. At present, business operations involve trading in raw materials, storing and processing raw materials into products to add value to raw materials before delivery to customers. Hence, the essential thing to have and invest in manufacturing is inventory. According to the Inventory Index Report [1] in 2019, the total inventory cost of Thailand was 967.40 billion baht, an increase of 924.60 billion baht from 2018 and a 4.6 percent growth rate. In 2019, the finished goods inventory index was 135.5 billion baht, an increase from 123.2 billion baht in 2018, reflecting an increase in the inventory of operators. This may result from selling fewer products than planned or producing more products than customers' requirements and may be the result of the slowdown in the domestic economy and the decline in imports and exports. While the Industrial Production Index was 101.6 billion baht, down from 105.4 billion baht in 2018, reflecting that operators have cut production due to the volatile situation of the world economy, which resulted in the contraction of exports. With the outbreak of COVID-19, companies that will be able to compete with competitors must have high competitive advantage. Therefore, reducing inventory or reducing inventory costs is a key factor in building competitiveness.

Inventory management is an integral part of company management or logistics management as inventory is a cost that is in every part of the production, for example, product manufacturing must have good raw materials, suitable and sufficient quantities for production and during production. Good production requires a reasonable period of time and no backlogs between productions. Consistent production results in low inventory. When the product is finished, it has to be delivered or prepared for the customer to pick up the product without the quantity of the finished product as it will affect the cost as well.

Inventory management is to find the right middle point in order not to have too much inventory because it will result in sunk cost. If the inventory is too low, it will affect production that may not be sufficient to produce. But if the raw material is purchased in large quantities, there may be a lower cost of purchasing raw materials. Therefore, inventory management is a sensitive matter and requires an understanding of the context and function of the inventory. The final aim of inventory management is to minimize the cost of managing your inventory 
because inventory has both advantages and disadvantages as mentioned above. To increase the efficiency and reduce costs to improve competitiveness, inventory management is the first priority.

Inventory management nowadays has an inventory management information system to help manage inventory quickly and accurately such as the general use of computer systems and the use of various systems for taking notes or importing information into the system, various display of inventory quantity, usage, and demand forecast. The introduction of information systems to help manage inventory is indispensable $[3,4]$.

The researcher therefore studies the factors of information technology, inventory control systems and inventory control practices that influence the competitive advantage of small and medium enterprises in the manufacturing industry in Thailand. Research results lead to the development and application of inventory management to suit small and medium enterprises in order to reduce inventory management costs and increase the competitiveness of small and medium enterprises in Thailand.

\section{Research Objectives}

1. To study the inventory management factors affecting the competitive advantage

2. To validate the model and confirm the inventory management factors affecting the competitive advantage.

\section{Literature Review}

Small and medium-sized enterprises in Thailand are currently receiving tremendous government support in terms of business funding, business expansion loan and business recovery loan to be able to resume business and compete in the future. In Thailand, Small and Medium Enterprises (SMEs) are divided into 3 categories: micro businesses employ no more than 5 people and earn not more than 1.8 million baht per year, small businesses employ no more than 50 people and earn not more than 100 million baht per year and medium enterprises (Medium) employing no more than 200 people and earning up to 500 million baht per year. Small and Medium Enterprises (SMEs) accounted for $35.30 \%$ of gross domestic product, which is one third of Thailand's GDP [1]. Small and medium enterprises in manufacturing are required to operate in manufacturing either. A must-have item for every production is inventory. Today's large-scale businesses have a precise and stable manufacturing system. It defines the needs of small and medium enterprises to take on the burden of managing their inventory in terms of quantity, quality, and delivery to the company according to their needs. Therefore, the cost of the small and medium enterprises companies to bear the cost of their inventory is also responsible for the cost of owning the inventory.

$[5,6]$ said inventory is a balancing act in the upstream to downstream supply chain. Maintaining proper inventory will not affect customer needs or the supply chain. Therefore, proper and effective inventory management has a direct and indirect effect on today's business profits.

[7-10] There are 7 types of traditional inventory: 1.Raw Material: the source material of production such as sheet iron, sheet rubber and material to be processed into goods 2. Work in Process: work in process or work waiting to be produced in the next step, such as unfinished phones and unfinished cars 3. Finished Goods: products that are finished and ready to be delivered to customers 4.Maintenance: parts or spare parts of machines that are prepared for replacement when the original machine part is broken or the part has reached the end of its life 5. Bought out parts: parts produced from one company are sent to manufacture to another, it is a finished product for one company, but is used as a raw material for another company, which can be found mostly in manufacture of printed circuit board electronic components 6. Packing Material: materials that must be prepared for packing products for customers such as cardboard boxes, boxes and plastic to cover products, cushioning material, adhesive or tape for product attachment and paper for labeling, currently added to the inventory category 7.Debris or broken parts: raw materials to be used or left over from production, are defective, of substandard quality, or cannot be utilized for their original purpose. These seven types of inventory are cross-dependent inventory ad must have in the production process, which occurs from the upstream to downstream of the downstream industry.

\section{Information Technology}

Today's small and medium enterprises have adopted information technology as an integral part of business development, for example, to develop a production system to be accurate, fast and keep up with demand and assist in the development of inventory management systems. Information technology is widely used in small and medium enterprises and plays a part in all areas of production, for example, using information technology to assist in production planning, enabling systematic planning and reducing management costs; transportation planning to provide transportation at the lowest transportation cost and human resource planning for the most efficient use of resources and the use of information in inventory management in order to systematically know the quantity of inventory. To implement information technology, it must be compatible with software and hardware. The 
hardware is based on the RFID BARCODE EDI EPOS to provide efficient, fast and accurate inventory management [4, 11] Inventory management information technology comprises both software and hardware [12]. Nowadays, radio frequency identification (RFID) technology is used to facilitate data transmission to enable data recording to be transmitted quickly $[13,14$ and makes stocktaking and inventory management more current and efficient $[12,15]$. Inventory management software for small and medium businesses started with the introduction of a package program (Microsoft Office). Companies with a medium or heavy workload may need inventory management software such as Materials Requirement Planning (MRP) and Enterprise Resource Planning (ERP). Managing in technology is to balance software and hardware and align it with the company for maximum performance.

Information technology can be applied to inventory management in small and medium businesses. The use of this technology must take into account the cost and skill of the employees. Therefore, choosing the right information technology to manage inventory, it is a matter that every company has to pay attention to in order to increase the efficiency of the company. In this research, information technology factors were divided into 3 areas: 1. Use of software and hardware for inventory management such as Electronic Point of sale (EPOS), Electronic Data Interchange Technology (EDI), Radio frequency identification (RFID) and BARCODE. 2. Linking information with suppliers and customers. 3. Using computers to help manage inventory $[2,15,16]$.

\section{Competitive Advantage}

Competitive advantage refers to differentiation or creating values that are unique and superior to competitors in the business. Satisfying customers requires a strategy that is consistent with the situation and low costs and differentiating products or services that are superior to competitors and quick response [17, 18]. It could be said that competitiveness at present is a must for SMEs to operate a business because competitiveness is the ability to differentiate a company's products or services. Differentiation has to be outstanding that it can attract customers to buy the company's products. Competitiveness can come from many things, such as product characteristics, product uniqueness, product quality, technology, superior functionality, maintenance and service. Therefore, competitiveness today focuses on three main areas [2, 19]1.Price - Since buying products nowadays have technology to help in buying or comparing prices easily, customers will choose to buy products at a similar price but with different functions. Customers tend to choose products with similar functions but at lower prices. In the same production, the raw material must be purchased with the lowest cost. 2. Quality - The quality of the product is another factor that the company gives as much importance as the price factor. This is because if the product is cheap but not of high quality, it will have to be bought in large quantities or multiple times in order to meet the objectives or production targets. Therefore, the quality factor is an important factor of competitiveness. 3. Delivery - The speed of delivery is an important factor in today's production. Most of today's production is based on the Just-in-Time Manufacturing (JIT) system. Because the JIT system is a system that does not store large volumes of inventory, but rather allows suppliers to store and deliver at a specified time. Therefore, delivery speed is an important factor to increase competitiveness, it can be concluded that competitiveness can be divided into 3 factors: 1) price, 2) quality and 3) delivery.

\subsection{Information Technology and Competitive Advantage}

Today's SMEs rely on modern information technology, easy access to information for a competitive advantage. Hence, to be able to gain a competitive advantage in time, it is necessary to rely on information technology that is accurate and fast in order to compete with low-cost competitive competitors including the production that requires information in production planning, planning of orders and effective inventory management in terms of lead time or inventory precision to reduce inventory management costs $[2,19]$.

\section{$\mathrm{H}_{1}$ Information Technology Influences Competitive Advantage}

\subsection{Information Technology (Information Technology) and Inventory Control Practices.}

There are several inventory control practices, for example, a fractional possibility analysis involves finding a practice that is considered in terms of cost, opportunity loss and profit-loss, introduction of information systems to enable faster inventory management and profit-loss calculation, consistent approach to meeting customer needs by applying information technology to forecasting customer needs to be precise and meet the needs of many changing customers and the use of information technology for forecasting sales and customer satisfaction is another practical approach to inventory management. Due to the large sales volume, inventory management must be appropriate and sufficient to meet customer needs in order for customers to be satisfied with the purchase of the company's products and services. Important factors of the inventory control practice: 1 . Cost reduction 2. Profits 3. Customer satisfaction 4. Sales $[4,5,20]$

$\mathrm{H}_{2}$ Information technology influences inventory control practices. 


\subsection{Inventory Control Practices and Competitive Advantages}

Inventory control practices focus on satisfying customers in terms of price responses that are competitive with competitors and cost management to be lower than competitors, including managing to be able to continuously profit in order to increase competitiveness.To be competitive today, SMEs rely on efficient inventory management in terms of cost, profitability and cost effectiveness and the ability to meet customer satisfaction as much as possible $[2,5,17,21]$.

$\mathrm{H}_{3}$ Inventory control practices influence competitiveness

\subsection{Inventory Control Systems and Inventory Control Practices}

Inventory Control Systems is a system that is used to control inventory in the warehouse most effectively such as increasing the quality of production in order to order raw materials in the right quantity without having to order for production, shortening the production cycle to reduce the size of the raw material order to reduce the cost of raw materials for each order and a reduction in storage space, as well as a reduction in inventory levels to a minimum, but still sufficient for production including a reduction in the delivery time to have a suitable delivery to ensure the inventory turnover appropriately. Therefore, there are 4 important factors in the inventory control system: 1.Increasing production quality 2 . Reducing cycle times 3 .Reduce the stock level 4 . Shorten the delivery time. The aforementioned factors influence inventory control practices in terms of shortening the cycle times leading to lower production costs and the production of quality products makes it possible to sell at a higher price and more profitable, as well as having a positive effect on the satisfaction of customers who get quality products at affordable prices [22-24].

$\mathrm{H}_{4}$ Inventory control systems influence inventory control practices.

\subsection{Inventory Control Systems with competitive ability}

Inventory control systems can greatly enhance competitiveness as inventory control systems focus on quality enhancement. If SMEs produce quality products and are different from competitors, it will increase their competitiveness over competitors. Having a good inventory control system for SMEs will help in reducing inventory levels and resulting in lower inventory management costs and continued business capital. It also increases the competitiveness and shortening the production time in order for the products to be produced faster, which increases the competitiveness because there are products that are released to customers quickly and continuously $[2,21]$

$\mathrm{H}_{5}$ Inventory control systems influence competitiveness.

The research variables can be summarized: 1. Information Technology (IT) 1.1 Using the software Inventory management hardware (IT1) 1.2. Information Links with Suppliers and Customers (IT2) 1.3. Using computers to assist in inventory management (IT3) 2. Inventory control system (ICS) 2.1 Increasing Production Quality (ICS1) 2.2 Reduction of Production Cycle (ICS2) 2.3. Downgrade of Stock Levels (ICS3) 2.4. Reduce Time Delivery (ICS4) 3.Inventory control practices (IP) 3.1. Cost reduction (IP1) 3.2 Profitability (IP2) 3.3 Customer Satisfaction (IP3) 3.4. Sales (IP4) 4. Competitiveness (CA) 4.1. Price (CA1) 4.2. Quality (CA2) 4.3. Fast delivery (CA3). It can be shown as Figure 1.

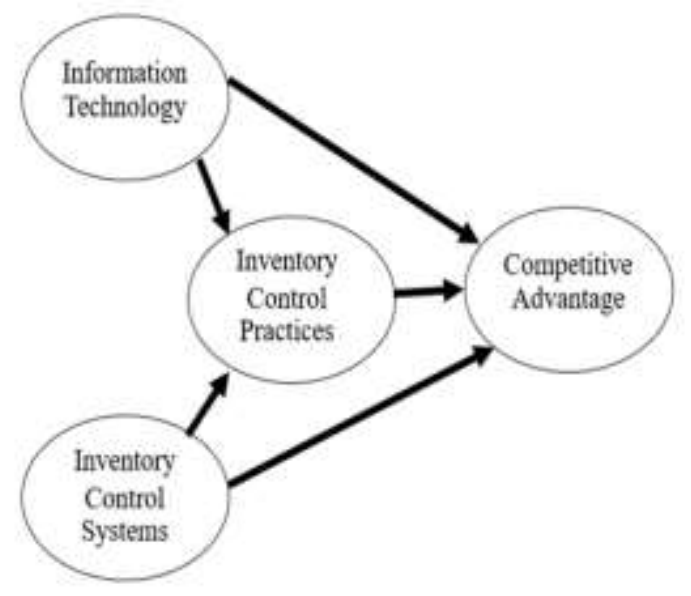

Figure 1: Concept model 


\section{Research scope}

The quantitative data was collected from the sample of 280 small and medium companies in Thailand[25]

\section{Research Methods}

This research was a blended research using quantitative research from collecting 280 samples of 517,899 Thai SMEs [1] and 14 observable variables [25]. From the SMEs industry in Thailand, the manufacturing sector used a five-point Likert scale questionnaire with IOC $=0.8-1.00$ and Cronbach's alpha $=0.89$. This questionnaire was self-answered and electronic. Qualitative research was a focus group from 9 experts working on inventory at supervisory level upwards using judgment sampling. The selection criteria were supervisor level or above and at least 10 years of inventory work experience as validation of the model researched through quantitative research.

\section{Research Results}

Research results from 280samples of SMEs were collected, including micro businesses, 21 companies (7.5\%), small businesses, 216 companies $(77.14 \%)$ and medium enterprises 43 companies (15.36\%). In the analysis of structural equations (SEM), there were 4 latent variables and a total of 14 observable variables. The interpretation of the results by Lisrel confirmed the consistency of the empirical data from the questionnaire to the model. The results showed that $\chi^{2}=106.32, \mathrm{df}=69, \chi^{2} / \mathrm{df}=1.54, \mathrm{CFI}=0.99, \mathrm{GFI}=0.95, \mathrm{SRMR}=0.042, \mathrm{RMSEA}=0.044$ passed the criteria of [25] and had a predictive coefficient of 57\%,shown in Figure 2.

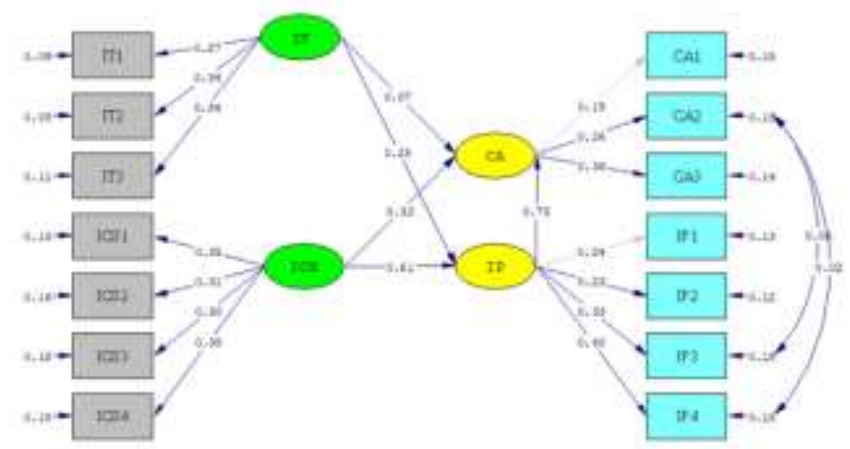

Figure 2: A causal model affecting competitiveness

From Figure 2,it was found that the causal model affecting competitiveness was consistent and harmonious with the empirical data and the total effect as shown in Table 1

Table 1: The total effect of the hypotheses

\begin{tabular}{|c|c|c|c|c|}
\hline Hypothesis & $\begin{array}{l}\text { Direct } \\
\text { Effect }\end{array}$ & $\begin{array}{c}\text { Indirect } \\
\text { Effect }\end{array}$ & $\begin{array}{l}\text { Total } \\
\text { Elect }\end{array}$ & Decision \\
\hline $\begin{array}{l}\text { Hi hformation technology influeviced } \\
\text { competitheness. }\end{array}$ & 00700 & 0.1825 & 0.2525 & $\begin{array}{c}\text { No } \\
\text { Accepted }\end{array}$ \\
\hline $\begin{array}{l}\text { He thionrution technodosy influenced inventory } \\
\text { control practices. }\end{array}$ & 0.2500 & + & 0.2500 & fictepted \\
\hline $\begin{array}{l}\text { Hi mventory control practices influenced } \\
\text { competitiveness }\end{array}$ & 07300 & - & 9.7300 & Accepled \\
\hline $\begin{array}{l}\text { Hi viventory control systems influenced imventory } \\
\text { control practices. }\end{array}$ & 0.6100 & 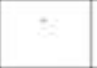 & 0.6100 & Accepted \\
\hline $\begin{array}{l}\text { 14 hiventory control systems hilluenced } \\
\text { compesitheress. }\end{array}$ & 0.3200 & 0.4953 & 0.7653 & Accepted \\
\hline
\end{tabular}

From Table 1, there were 5 assumptions and 4 qualified hypotheses with descending influence as follows: 1 . H5: Inventory control system influenced competitiveness and had influence $=0.7653$ and had direct influence $=$ 0.3200 . And indirect influence $=0.4453,2$. H3: Inventory control practice influenced competitiveness and direct influence $=0.7300,3$. H4: Inventory control system influenced inventory control practices and has direct influence $=0.6100,4 . \mathrm{H} 2$ : Information technology influenced inventory control practices and has direct influence $=0.2500$ and the hypotheses that are not passed were H1: Information Technology influenced on Competitiveness and Influence $=0.2525$; direct influence $=0.0700$ and indirect influence $=0.1825$.

The qualitative research was focus group from 9 inventory management experts to verify empirical model. The focus group results were in the same direction, they agree with this model. As a result, most of the focus groups focused on managing inventory control practices, as it controlled cost, profit and sales, as well as customer satisfaction that is critical to competitiveness. The focus group also focused on information technology influencing competitiveness, but this was an unqualified hypothesis. This was because information technology in 
inventory management will be information technology that relies on warehouse management in order to make inventory management more efficient and affect its competitiveness.

\section{Conclusion}

This research was a research on inventory management factors affecting competitiveness through a combination of research. The research examined the influence of information technology factors, inventory control practice factors, and inventory control factors influencing competitiveness. The relationship could be summarized as follows:

Information technology had no influence on competitiveness because information technology had no direct influence on competitiveness. The information technology used in the inventory management system could not be effectively operated without a guideline for practice that is consistent with [2]. However, information technology is an indirect factor affecting competitiveness because to be competitive with competitors, the speed and accuracy of information technology was still necessary.

Information technology influenced inventory control practices that were aligned with [4], this is because information technology was a key factor in driving effective inventory control practices such as reducing costs or increasing profits, using information technology to use resources efficiently, selection of low-cost raw material sourcing technology and use of information to find products or raw materials in real-time and with accuracy

Inventory control practices influenced competitiveness, consistent with [21] because inventory control practices focused on reducing costs and maximizing profitability in order to gain competitive advantage. Much of the competitive advantage was focused on cost, quality and delivery, in line with inventory control practices because inventory management can be improved or developed within the company from the implementation of guidelines that are appropriate to the context of each SMEs.

Inventory control systems influence inventory control practices. These two factors were consistent. The inventory control system was an improvement in warehouse practices that manage inventory effectively, Instead, inventory control practices focused on the results of inventory control operations by measuring costs and profits . Therefore, an effective inventory control system would lead to lower costs and further profitability, which is consistent with [24].

Inventory control system had an influence on competitiveness. Inventory control systems focused on quality control and delivery timing, in line with quality-focused competitiveness in order to provide customers with quality products at the time required by the customer. Moreover, reducing cycle times could deliver products to customers more quickly and efficiently. It was indispensable to reduce inventory levels, which was a reduction in inventory levels to meet demand. This downgraded in stock was a direct cost reduction and allows for an effective increase in competitiveness, in line with $[2,21]$.

This research had made a new discovery that information technology has no influence on the competitiveness of SMEs in Thailand. This was because information technology may not directly affect competitiveness but indirectly affect competitiveness. Due to the fact that information technology must be used in conjunction with appropriate inventory control practices, including the use of information technology appropriate to the context of each SMEs inventory in Thailand.

\section{Suggestions}

1. Further research should increase the variables related to inventory management and competitiveness such as organizational efficiency and supplier performance, etc.

2. This research did not categorize SMEs in the research, so further research should be compared between micro businesses, small Business and medium business for greater clarity of research.

\section{References}

Office of the National Economic and Social Development Council, "THAILAND'S LOGISTICS REPORT 2019," Office of the National Economic and Social Development Council2020.

V. W. Naliaka and G. S. Namusonge, "Role of Inventory Management on Competitive Advantage among Manufacturing Firms in Kenya: A Case Study of Unga Group Limited," International Journal of Academic Research in Business and Social Sciences, vol. 5, pp. 87-104, 2015.

M. Rahman, C. Mordi, and U. Nwagbara, "Factors influencing E-HRM implementation in government organisations," Journal of Enterprise Information Management, vol. 31, pp. 247-275, 2018.

Z. T. M. Tuan, R. M. J. Nor, A. A. A. Maz, and R. H. Mohd, "INFLUENCE OF INFORMATION TECHNOLOGY,SKILLS AND KNOWLEDGE, AND FINANCIAL RESOURCES ON INVENTORY 
MANAGEMENT PRACTICES AMONGST SMALL AND MEDIUM RETAILERS IN MALAYSIA," Asia-Pacific Management Accounting Journal, vol. 13, pp. 173-200, 2018.

K. L. Wangari and A. W. Kagiri, "INFLUENCE OF INVENTORY MANAGEMENT PRACTICES ON ORGANIZATIONAL COMPETITIVENESS: A CASE OF SAFARICOM KENYA LTD," International Academic Journal of Procurement and Supply Chain Management, vol. 1, pp. 72-98, 2015.

K. Pornthep, S. Theathanick, and K. Kanreutai, "Supplier Management Factors Affecting Inventory in Small and Medium-sized Electronics and Electrical Parts Manufacturers," Journal of Business Economics and Communications, vol. 15, pp. 83-98, 2020.

S. A. Mohammad and A. M. Akram, "Inventory management, cost of capital and firm performance: evidence from manufacturing firms in Jordan," Investment Management and Financial Innovations, vol. 14, pp. 4-14, 2017.

R. Patil and G. Singh, "Inventory management and analysis in an orthodontic practice," Seminars in Orthodontics, vol. 22, pp. 280-288, 2016.

P. Vrat. (2014). Basic Concepts in Inventory Management. Available: https://link.springer.com/chapter/10.1007\%2F978-81-322-1970-5_2

S. Banterng, S. Charcrit, S. Theathanick, and K. Kanreutai, "Guidelines for Waste Management in the Plastics Industry in Thailand," BU ACADEMIC REVIEW, vol. 19, pp. 164-176, 2020.

V. A.-S. Sonia, F. A.-G. Jonnatan, G.-R. Heriberto, C. Maria, Bermeo-Samaniego, K. C.-J. Ana, et al., "A glance of industry 4.0 at supply chain and inventory management," International Journal of Industrial Engineering,, vol. 26, pp. 486-506, 2019.

Y. Lin, B. Liang, and X. Zhu, "The effect of inventory performance on product quality," International Journal of Quality \& Reliability Management, vol. 35, pp. 2227-2247, 2018.

R. Nayak, A. Singh, R. Padhye, and L. Wang, "RFID in textile and clothing manufacturing: technology and challenges," Fashion and Textiles, vol. 2, 2015.

S. S. Kitheka and O. O. Gerald, "Inventory Management Automation and The Performance of Supermarkets in Western Kenya," International Journal of Research in Management \& Business Studies, vol. 1, pp. 9-18, 2014.

S. Goyal, B. C. Hardgrave, J. A. Aloysius, and N. DeHoratius, "The effectiveness of RFID in backroom and sales floor inventory management," The International Journal of Logistics Management, vol. 27, pp. 795-815, 2016.

A. Pignault and C. Houssemand, "Construction and initial validation of the Work Context Inventory," Journal of Vocational Behavior, vol. 92, pp. 1-11, 2016.

M. Atchara, "The Competitive Advantage of Agricultural Processing Industry SMEs Entrepreneurs in Upper Northern Region, Thailand," Journal of Yala Rajabhat University, vol. 12, pp. 13-26, 2017.

K. Pensuk, L. Woraluck, T. Siriluck, and J. Korkaew, "Competitive Advantage of SMEs in Thailand 4.0," Journal of Humanities and Social Sciences Mahasarakham University, vol. 37, pp. 245-256, 2018.

D. Atnafu, A. Balda, and S. Liu, "The impact of inventory management practice on firms' competitiveness and organizational performance: Empirical evidence from micro and small enterprises in Ethiopia," Cogent Business \& Management, vol. 5, pp. 1-16, 2018.

K. Sharipbekova and Z. Raimbekov, "Influence of Logistics Efficiency on Economic Growth of the CIS Countries," European Research Studies Journal, vol. 21, pp. 678-690, 2018.

P. Yaowapa, C. Chotirus, S. Ream, S. Rattapon, and S. Mira, "Competitiveness Evaluation of SME Shoe Businesses in Thailand to the ASEAN Market," NIDA BUSINESS JOURNAL, vol. 21, pp. 45-65, 2017.

S. Dwivedi, A. kumar, and P. kothiyal, "Inventory Management: A Tool of Identifying Items That Need Greater Attention for Control," The Pharma Journal vol. 1, pp. 125-125, 2012.

S. Sindhu, K. Nirmalkumar, and V. Krishnamoorthy, "Performance Analysis of Inventory Management System in Construction Industries in India," International Journal of Innovative Research in Science,Engineering and Technology, vol. 3, pp. 11488-11493, 2014.

A. Haji, M. Afzalabadi, and R. Haji, "Pricing and inventory decisions in a vendor managed inventory system with revenue sharing contract," Uncertain Supply Chain Management, vol. 2018, pp. 299-320, 2018.

J. F. Hair, W. C. Black, B. J. Babin, and R. E. Anderson, Multivariate Data Analysis vol. 7: Pearson New International Edition, 2014. 